\title{
The Relationship Between N-Terminal Pro-Brain Natriuretic Peptide Level and Left Ventricular Metabolic Index in Patients with Heart Failure with Mildly Reduced Ejection Fraction
}

\author{
๑ Mehmet Kış1, ๑ Oktay Şenöz², ๑ Tuncay Güzel ${ }^{3}$
}

${ }^{1}$ Dokuz Eylül University Faculty of Medicine, Department of Cardiology, İzmir, Turkey

${ }^{2}$ Bakırçay University, Çiğli Training and Research Hospital, Department of Cardiology, İzmir, Turkey

${ }^{3}$ Diyarbakır Gazi Yaşargil Training and Research Hospital, Clinic of Cardiology, Diyarbakır, Turkey

\section{Abstract}

Objectives: It has been determined that mortality and hospitalization rates due to cardiovascular diseases are higher in patients with left ventricular hypertrophy (LVH). In addition, LVH has been shown to be an independent risk factor for heart failure (HF). Previous studies in this area have focused more on preserved and low ejection fraction HF. Therefore, we aimed to contribute to the literature by investigating the relationship between $\mathrm{N}$-terminal pro-brain natriuretic peptide level (NT-proBNP) and left ventricular metabolic index (LVMI) in heart failure with mildly reduced ejection fraction (HFmrEF).

Materials and Methods: Between January 2018 and October 2021, 213 patients diagnosed with heart failure with mildly reduced ejection fraction were included in the study. This study was designed as cross-sectional. The patients were divided into two groups according to their gender, as those with normal and abnormal LVMI. Pearson's correlations were used to assess the correlations between LVMI and NT-proBNP. A ROC curve was plotted to determine the diagnostic reliability of plasma concentration of NT-proBNP on LVMI.

Results: There were 90 patients in Group 1 (patients with normal LVMI) and 123 patients in Group 2 (patients with high LVMI). The mean LVMI value was $94.37( \pm 11.10) \mathrm{g} / \mathrm{m}^{2}$ in Group 1 and $119.64( \pm 15.90) \mathrm{g} / \mathrm{m}^{2}$ in Group 2. The mean NT-

Address for Correspondence: Mehmet Kış, Dokuz Eylül University Faculty of Medicine, Department of Cardiology, İzmir, Turkey e-mail: drmehmet.kis@hotmail.com ORCID: orcid.org/0000-0003-0775-8992

Received: 01.12.2021 Accepted: 05.01.2022

Cite this article as: Kış M, Şenöz O, Güzel T. The Relationship Between N-Terminal Pro-Brain Natriuretic Peptide Level and Left Ventricular Metabolic Index in Patients with Heart Failure with Mildly Reduced Ejection Fraction. EJCM 2022;10(1):4-11.

DOI: 10.32596/ejcm.galenos.2022.2021-12-063

${ }^{\circ}$ Copyright 2022 by Heart and Health Foundation of Turkey (TÜSAV) / E Journal of Cardiovascular Medicine published by Galenos Publishing House. 


\section{Abstract}

proBNP level was found to be $941.57( \pm 1190.81) \mathrm{pg} / \mathrm{ml}$. NT-proBNP levels were statistically significantly higher in Group 2 than in Group $1(1138.49 \pm 1330.7$ vs. $672.46 \pm 907.52, \mathrm{p}=0.005)$. The relationship between NT-proBNP $(941.57 \pm 1190.81$ $\mathrm{pg} / \mathrm{mL})$ levels and LVMI $\left(108.96 \pm 18.81 \mathrm{~g} / \mathrm{m}^{2}\right)$ was tested by the Pearson correlation. A moderate, positive and significant relationship was found between these variables $[\mathrm{r}(211)=0.368, \mathrm{p}<0.001]$. NT-proBNP $>342 \mathrm{pg} / \mathrm{mL}$ had $57 \%$ sensitivity and $58 \%$ specificity [receiver operating characteristic (ROC) area under curve: $0.620,95 \% \mathrm{CI}: 0.544-0.695, \mathrm{p}=0.003$ ] for determining LVMI.

Conclusion: In patients with heart failure with mildly reduced ejection fraction, high NT-proBNP levels can predict LVMI elevation, which is an indicator of LVH. In this patient group, especially female gender and renal dysfunction may be risk factors for high LVMI.

Keywords: Mildly reduced ejection fraction, NT-proBNP, left ventricular metabolic index

\section{Introduction}

The plasma concentration of the cardiac natriuretic peptide, N-terminal pro-brain natriuretic peptide (NTproBNP), is tightly correlated with cardiac function ${ }^{(1)}$. The increased release of NT-proBNP into the bloodstream by cardiac myocytes may be the result of left ventricular hypertrophy (LVH), high ventricular wall stress, or volume overload. Therefore, these peptides may have the potential to increase the efficacy of treatment strategies, as well as being diagnostic and prognostically significant biomarkers for patients with heart failure $(\mathrm{HF})^{(2,3)}$.

A diagnosis of heart failure with mildly reduced ejection fraction (HFmrEF) include the presence of symptoms and/ or signs of HF, a high natriuretic peptide, and a slightly decreased EF (41\%-49\%) ${ }^{(4)}$. NT-pro-BNP measured at rest was recognized a diagnostic and prognostic biomarker of HF with reduced ejection fraction (HFrEF); however, its value in HFmrEF has not been fully determined ${ }^{(5)}$. The presence of high natriuretic peptides (BNP $\geq 35 \mathrm{pg} / \mathrm{mL}$ or NT proBNP $\geq 125 \mathrm{pg} / \mathrm{mL}$ ) and evidence of structural heart disease make the diagnosis more likely, but it is stated that it is not mandatory if there is certainty regarding left ventricular ejection fraction (LVEF) measurement ${ }^{(4,5)}$.

From an echocardiographic point of view, mortality and hospitalization rates due to cardiovascular diseases were found to be higher in patients with left ventricular dysfunction and $\mathrm{LVH}^{(6)}$. In addition, $\mathrm{LVH}$ is an independent risk factor for $\mathrm{HF}^{(7)}$. Left ventricular mass (LVM) estimates have traditionally been indexed to body size and yielded the LVM index (LVMI) if corrected for body surface $\operatorname{area}^{(8)}$.

In our study, we aimed to investigate the relationship between NT-proBNP level and LVMI in the heart failure patient population with mildly reduced ejection fraction.

\section{Materials and Methods}

Ethics committee approval of our study was obtained from İzmir Bakırçay University Non-Interventional Clinical Research Ethics Committee on 10.11.2021 with decision number 380 .

Between January 2018 and October 2021, 213 consecutive patients diagnosed with HFmrEF were included in the study. After the study was explained in detail to the patients included in the study, signed voluntary consent forms were obtained. Patients younger than 18 years of age, patients with hypertrophic cardiomyopathy, severe renal and liver failure, active malignancies, acute coronary syndrome, cardiogenic shock, inability to perform optimal echocardiographic and ultrasonographic examination, and those who did not give informed voluntary consent were excluded from the study. 
Patients older than 18 years of age, patients who were diagnosed with HFmrEF, and who gave informed voluntary consent were included in the study. The study was designed as a retrospective, cross sectional. Demographic data, biochemical parameters and imaging findings of the patients were recorded.

The patients were analyzed by dividing them into two groups as those with normal and abnormal LVMI. Group 1 consisted of patients with normal LVMI and Group 2 consisted of patients with abnormal LVMI. Abnormal LVMI cut-off value was accepted as $>115 \mathrm{~g} / \mathrm{m}^{2}$ in males and $>95 \mathrm{~g} / \mathrm{m}^{2}$ in females ${ }^{(9)}$.

\section{NT-proBNP Measurement}

NT-proBNP level was measured quantitatively with the Elecsys proBNP device (Roche Diagnostics, Mannheim, Germany) using the electrochemiluminescence immunoassay method ${ }^{(10,11)}$.

\section{Echocardiography}

Echocardiographic examination of the patients was performed using Vivid S6, GE Medical Systems, USA device. In accordance with the standard procedures of the American Society of Echocardiography; evaluation was made through parasternal short axis, long axis and apical four-chamber windows ${ }^{(12)}$. Left ventricular dimensions were measured using M-mode echocardiography from the parasternal long axis, including end-diastole ventricular internal diameter (LVIDd), end-diastole interventricular septal thickness (IVST), and posterior wall thickness (PWT), while other cardiac chambers were measured from the apical four-chambers. LVEF was evaluated from four chambers with the modified Simpson's method. LVM was calculated with the Devereux formula ${ }^{(13)}$. LVMI was calculated by dividing the LVM to body surface area. For the measurement of the IVS and PWT, the average of the measurements was taken from the parasternal long axis using two-dimensional and M-mode techniques.

\section{Statistical Analysis}

Statistical analyses were performed using SPSS (version 15.0, SPSS Inc., Chicago, Illinois). The normal distribution of data was evaluated with the KolmogorovSmirnov test. Continuous variables were shown as mean \pm standard deviation (SD). Categorical variables were presented as frequency and percentage. Continuous variable groups were compared using the independent Student's t-test or the Mann-Whitney U test according to normality distribution. The chi-square test or Fisher's exact test was used to compare categorical variables. Receiver operating characteristics (ROC) curve analysis was applied to determine the optimal cut-off level for predicting LVH. The Pearson's correlations were used to assess the correlations between LVMI and NT-proBNP. The significance level for all hypotheses was accepted as $<0.05$.

\section{Results}

Two hundred and thirteen patients who met the inclusion criteria were included in the study. There were 90 patients in Group 1 (patients with normal LVMI) and 123 patients in Group 2 (patients with high LVMI). The mean age of the study population was $64.8( \pm 16.18)$ years, and there was no statistical difference in age between the two groups $(\mathrm{p}=0.507)$. However, the female sex ratio was significantly higher in Group 2 than in Group 1 (83.7\% vs. $34.4 \%, \mathrm{p}<0.001)$. Non-ischemic etiology comprised $36.2 \%$ of the entire population, and there was no significant difference between the groups in terms of ischemic and non-ischemic etiology.

Coronary artery disease (64.8\%) and hypertension (HT) $(62.9 \%)$ were the most common comorbid diseases, and there was no statistically significant difference between the two groups $(67.8 \%$ vs. $62.2 \%, \mathrm{p}=0.435,56.7 \%$ vs. $67.5 \%, \mathrm{p}=0.107$ respectively). Diabetes mellitus and hyperlipidemia were the following diseases with a rate of $26.3 \%$ and $22.1 \%$, respectively. Demographic and clinical data of the patients included in the study are summarized in Table 1. 
From biochemical parameters, mean urea value [31.66 $( \pm 18.86)$ vs. $24.79( \pm 15.19)]$, creatinine value $[1.08( \pm 0.64)$ vs. $0.92( \pm 0.37)]$, and ferritin value [199.92 $( \pm 255.54)$ vs. $110.45( \pm 123.87)]$ were found to be higher in Group 2 than in Group $1(p=0.004,0.03$, and 0.0123 , respectively).

The mean of Nt-proBNP was found to be 941.57 $( \pm 1190.8) \mathrm{pg} / \mathrm{mL}$. It was statistically significantly higher in Group 2 [1138.49 $( \pm 1330.7)]$ than in Group 1 [672.46 $( \pm 907.52)](p=0.005)$. Laboratory data are presented in Table 2.

In the echocardiography, LVEF value of the patients was $45.28( \pm 2.96) \%$. Moderate-severe mitral regurgitation (MR) was seen in $41.8 \%$, moderate-severe mitral stenosis (MS) in $6.6 \%$, and moderate-severe aortic regurgitation (AR) in $10.8 \%$. There was no significant difference between the groups in terms of moderate-severe valve disease and LVEF. The echocardiographic features of the patients are presented in Table 3.

Group 1 consisted of patients with a normal LVMI and no LVH, and the mean LVMI value was $94.37( \pm 11.10) \mathrm{g} /$ $\mathrm{m}^{2}$. Group 2 consisted of patients with a higher LVMI and found to have LVH. The mean LVMI value of Group 2 was determined as $119.64( \pm 15.90) \mathrm{g} / \mathrm{m}^{2}$, and it was statistically significantly higher than that of Group $1(\mathrm{p}<0.001)$.

The most commonly used drugs by the patients are beta-blockers with the rate of $68.5 \%$, antiaggregants with the rate of $55.9 \%$ and loop diuretics with the rate of $42.3 \%$. The rate of using anticoagulants is $25.4 \%$ and the rate of using aldosterone antagonist is $27.7 \%$. There was no statistically significant difference between the groups in terms of drugs used. This situation increases the strength of our study. Treatments of the study population are summarized in Table 4.

The relationship between NT-proBNP $(941.57 \pm 1190.81$ $\mathrm{pg} / \mathrm{mL})$ levels and LVMI $\left(108.96 \pm 18.81 \mathrm{~g} / \mathrm{m}^{2}\right)$ was tested with Pearson's correlation. A moderate, positive and significant relationship was found between these variables $[\mathrm{r}(211)=0.368, \mathrm{p}<0.001]$ (Figure 1).

NT-proBNP $>342 \mathrm{pg} / \mathrm{mL}$ had $57 \%$ sensitivity and 58\% specificity (ROC area under curve: $0.620,95 \%$ CI: $0.544-$ $0.695, \mathrm{p}=0.003$ ) for determining the LVMI (Figure 2).

Table 1. Baseline demographic and clinical characteristics of the study population

\begin{tabular}{|c|c|c|c|c|}
\hline Variables & $\begin{array}{l}\text { Group } 1 \\
(n=90)\end{array}$ & $\begin{array}{l}\text { Group } 2 \\
(n=123)\end{array}$ & $\begin{array}{l}\text { Total } \\
(n=213)\end{array}$ & p-value \\
\hline Age (years), mean \pm SD & $64.2( \pm 12.7)$ & $65.3( \pm 13.4)$ & $64.8( \pm 13.1)$ & 0.507 \\
\hline Female sex, $\mathrm{n}(\%)$ & $31(34.4)$ & $103(83.7)$ & $134(62.9)$ & $<0.001$ \\
\hline Hypertension, n (\%) & $51(56.7)$ & $83(67.5)$ & $134(62.9)$ & 0.107 \\
\hline Diabetes mellitus, n (\%) & $25(27.8)$ & $31(25.2)$ & $56(26.3)$ & 0.673 \\
\hline CAD, n (\%) & $61(67.8)$ & $77(62.6)$ & $138(64.8)$ & 0.435 \\
\hline COPD, n (\%) & $6(6.7)$ & $16(13.0)$ & $22(10.3)$ & 0.133 \\
\hline CRF, n (\%) & $7(7.8)$ & $20(16.3)$ & $27(12.7)$ & 0.066 \\
\hline Peripheral artery disease, $\mathrm{n}(\%)$ & $7(7.8)$ & $4(3.3)$ & $11(5.2)$ & 0.140 \\
\hline CVD, n (\%) & $13(14.4)$ & $9(7.3)$ & $22(10.3)$ & 0.091 \\
\hline Anemia, n (\%) & $14(15.6)$ & $23(18.7)$ & $37(17.4)$ & 0.550 \\
\hline Non-ischemic etiology, n (\%) & $30(33.3)$ & $47(38.2)$ & $77(36.2)$ & 0.464 \\
\hline
\end{tabular}




\section{Discussion}

In this study, we found a positive correlation between NT-proBNP level and LVMI, which is an indicator of $\mathrm{LVH}$, in HFmrEF patients.

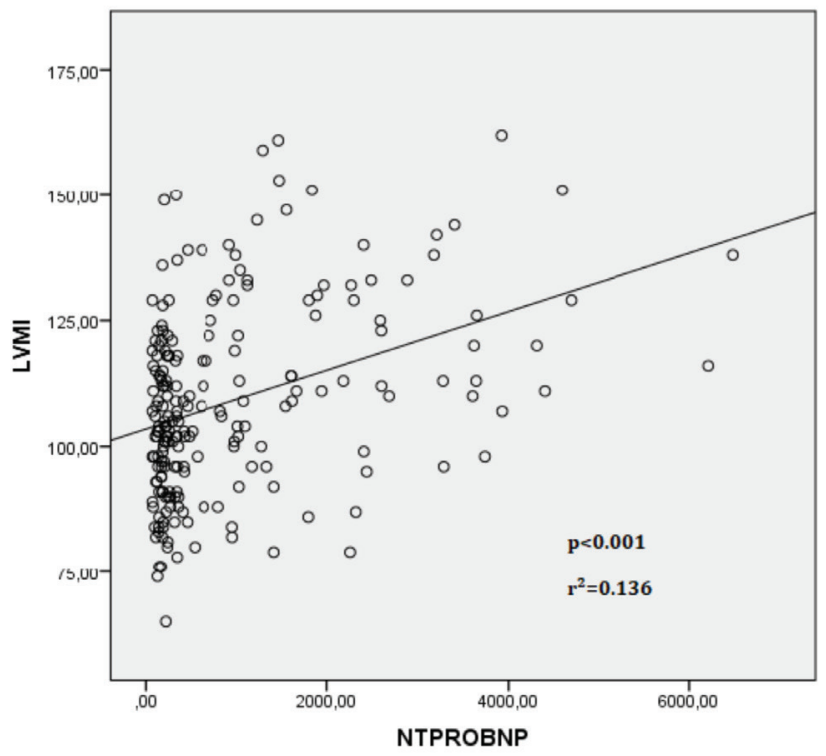

Figure 1. Correlation between NT-proBNP and LVMI in heart failure with mildly reduced ejection fraction

NT-proBNP: N-terminal pro-brain natriuretic peptide level, LVMI: Left ventricular metabolic index

Table 2. Baseline laboratory parameters of the patients

\begin{tabular}{|c|c|c|c|c|}
\hline $\begin{array}{l}\text { Variables } \\
\text { (Mean } \pm \text { SD) }\end{array}$ & $\begin{array}{l}\text { Group } 1 \\
(n=90)\end{array}$ & $\begin{array}{l}\text { Group } 2 \\
(n=123)\end{array}$ & $\begin{array}{l}\text { Total } \\
(n=213)\end{array}$ & p-value \\
\hline Urea, mg/dL & $24.79 \pm 15.19$ & $31.66 \pm 18.86$ & $27.68 \pm 17.13$ & 0.004 \\
\hline Creatinine, $\mathrm{mg} / \mathrm{dL}$ & $0.92 \pm 0.37$ & $1.08 \pm 0.64$ & $1.01 \pm 0.55$ & 0.03 \\
\hline Uric acid, mg/dL & $5.36 \pm 2.16$ & $5.21 \pm 1.52$ & $5.3 \pm 1.92$ & 0.627 \\
\hline Nt-ProBNP, pg/mL & $672.46 \pm 907.52$ & $1138.49 \pm 1330.7$ & $941.57 \pm 1190.8$ & 0.005 \\
\hline WBC, $10^{9} / \mathrm{L}$ & $8.27 \pm 3.15$ & $8.38 \pm 7.70$ & $8.33 \pm 2.89$ & 0.438 \\
\hline Ferritin, ng/mL & $110.45 \pm 123.87$ & $199.92 \pm 255.54$ & $158.12 \pm 209.08$ & 0.013 \\
\hline Fasting glucose, $\mathrm{mg} / \mathrm{dL}$ & $115.42 \pm 40.12$ & $118.31 \pm 42.37$ & $117.08 \pm 41.35$ & 0.307 \\
\hline $\mathrm{TSH}, \mathrm{mU} / \mathrm{L}$ & $1.69 \pm 1.56$ & $1.41 \pm 1.20$ & $1.53 \pm 1.38$ & 0.067 \\
\hline $\mathrm{Ca}, \mathrm{mg} / \mathrm{dL}$ & $9.28 \pm 0.54$ & $9.16 \pm 0.65$ & $9.21 \pm 0.61$ & 0.159 \\
\hline
\end{tabular}


sensitivity and specificity of NT-proBNP in the diagnosis of $\mathrm{HFrEF}^{(14)}$. There are also studies on the relationship between NT-proBNP and LVH in the population without HF. However, it has not been adequately studied in patients with HFmrEF.

Lubien et al. ${ }^{(15)}$ found that high peptide levels were an accurate indicator of diastolic abnormalities detected by echocardiography, regardless of the patient's history or the signs and symptoms of congestive HF. In a study that included 313 asymptomatic patients (51\% female, mean age: 61 years) with HT and diastolic dysfunction, higher NT-proBNP was associated with a greater LVMI $(p=0.003)$. In conclusion, elevation in natriuretic peptide levels was found to be predominantly associated with subclinical

Table 3. Echocardiographic features of the patients

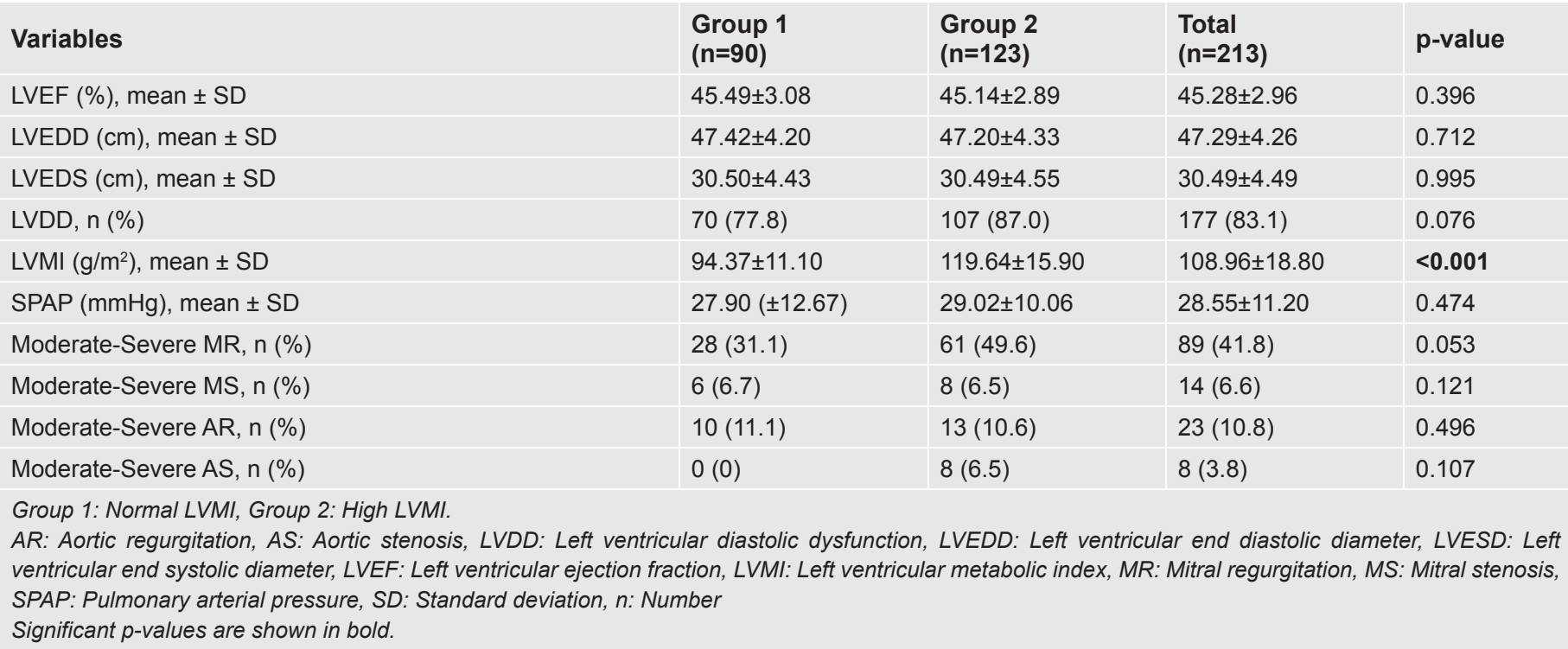

Table 4. Medications used by the patients

\begin{tabular}{|c|c|c|c|c|}
\hline Medications & $\begin{array}{l}\text { Group } 1 \\
(n=90)\end{array}$ & $\begin{array}{l}\text { Group } 2 \\
(n=123)\end{array}$ & $\begin{array}{l}\text { Total } \\
(n=213)\end{array}$ & p-value \\
\hline Betablockers, n (\%) & $62(68.9)$ & $84(68.3)$ & $146(68.5)$ & 0.926 \\
\hline Statine, n (\%) & $33(36.7)$ & $38(30.9)$ & $71(33.4)$ & 0.377 \\
\hline Antiaggregant, $\mathrm{n}(\%)$ & $54(60.0)$ & $65(52.8)$ & $119(55.9)$ & 0.299 \\
\hline Anticoagulant, $\mathrm{n}(\%)$ & $21(23.3)$ & $33(26.8)$ & $54(25.4)$ & 0.984 \\
\hline Loop diuretic, n (\%) & $42(46.7)$ & $48(39.0)$ & $90(42.3)$ & 0.265 \\
\hline Aldosterone antagonist, n (\%) & $23(25.6)$ & $36(29.3)$ & $59(27.7)$ & 0.550 \\
\hline Thiazide diuretic, n (\%) & $14(15.6)$ & $13(10.6)$ & $27(12.7)$ & 0.280 \\
\hline Non-dihidropiridine CCB, n (\%) & $5(5.6)$ & $6(4.9)$ & $11(5.2)$ & 0.825 \\
\hline Digoxin, n (\%) & $3(3.3)$ & $7(5.7)$ & $10(4.7)$ & 0.422 \\
\hline
\end{tabular}


diastolic dysfunction in asymptomatic hypertensive heart disease and preserved ejection fraction ${ }^{(16)}$.

Talwar et al. ${ }^{(17)}$ found that the presence of HT did not affect NT proBNP concentrations in patients with or without LVH. In this study, we wanted to show the relationship between LVMI and NT-proBNP levels in patients with HFmrEF. We found that NT-proBNP levels were significantly higher in patients with HFmEF and high LVMI.

A study including 662 patients, which was conducted to investigate the relationship between NT-proBNP quartiles and $\mathrm{LVH}$ risk in patients without $\mathrm{HF}$ and to evaluate the relationship between NT-proBNP and the hallmarks of LVH, showed a progressive increase in LVH formation with increasing NT proBNP quartiles in patients without HF. In addition, significant positive linear relationships of $\mathrm{Lg}(\mathrm{NT}-$ proBNP) with $\mathrm{LVM}$ and LVMI were determined ${ }^{(18)}$.

Likewise, NT-proBNP levels were compared in patients with LVH in a population study that included 215 patients with and without a diagnosis of HT, with findings supporting our study. It was shown that NTproBNP was increased in both groups. It has been demonstrated that the presence of HT in LV hypertrophy does not significantly affect peptide levels ${ }^{(19)}$.

In another study investigating the diagnostic value of NT-proBNP level to detect LVH in hypertensive patients with HFpEF, 27 patients with a diagnosis of essential HT were included. A significant correlation was found between LVM determined by magnetic resonance imaging and plasma NT-proBNP concentration $(r=0.598$; $\mathrm{p}=0.001)^{(20)}$. The main limitation of this study is that the number of patients studied was small and only patients with sinus rhythm were included in the study. In our study, pre-study power analysis was performed, and the number of patients was larger and not only those with sinus rhythm but also all patients with HFmrEF were included, regardless of rhythm. This is another advantage of our work.
The use of antihypertensive drugs may alter BNP concentrations. Beta-blockers, ACE inhibitors, and diuretics may have variable effects on circulating BNP concentrations $^{(21)}$. The fact that there was no statistically significant difference in terms of the drugs used in both groups in our study is one of the most important parameters that increases the power of the study.

When the sensitivity and specificity of NT-proBNP with HFmrEF in detecting LVH were tested with the ROC curve, we found that NT-proBNP level of $342 \mathrm{pg} / \mathrm{mL}$ and above had moderate sensitivity (57\%) and specificity (58\%) for detecting LVH. Although this result suggests that NT-proBNP cannot be used as an ideal screening test for LVH in HFmrEF in clinical use, it may show that it can be a very useful test for confirming the diagnosis when used together with other methods such as echocardiography.

\section{Study Limitations}

The present study has some limitations. The most important of these is the retrospective design of the study. NT-proBNP was found to be a predictor of LVH detection in HFmrEF patients, but the sensitivity and specificity were weak at the determined cut-off value.

\section{Conclusion}

Plasma Ntpro-BNP levels are useful in determining left ventricular metabolic index elevation, which is an indicator of left ventricular hypertrophy, in patients with heart failure with mildly reduced ejection fraction. It may be useful to rule out left ventricular hypertrophy in this patient population.

\section{Ethics}

Ethics Committee Approval: Ethics committee approval was obtained from İzmir Bakırçay University Non-Interventional Clinical Research Ethics Committee on 10.11.2021 with decision number 380 .

Informed Consent: Signed voluntary consent forms were obtained from all patients who include in this study.

Peer-review: Externally peer-reviewed. 


\section{Authorship Contributions}

Concept: M.K., Design: M.K., Data Collection and/ or Processing: T.G., Analysis and Interpretation: O.Ş., Supervision: O.Ş. Writing: M.K.

Conflict of Interest: No conflict of interest was declared by the authors.

Financial Disclosure: No financial resources have been used for this article.

\section{References}

1. Gupta DK, Wang TJ. Natriuretic peptides and cardiometabolic. Health Circ J 2015;79:1647-55.

2. Santaguida PL, Don-Wauchope AC, Oremus M, et al. BNP and NT-probNP as prognostic markers in persons with acute decompensated heart failure: A systematic review. Heart Fail Rev 2014;19:453-70.

3. Ponikowski P, Voors AA, Anker SD, et al. 2016 ESC guidelines for the diagnosis and treatment of acute and chronic heart failure. Kardiol Pol 2016;74:1037-147.

4. McDonagh TA, Metra M, Adamo M, et al. 2021 ESC Guidelines for the diagnosis and treatment of acute and chronic heart failure. Eur Heart $\mathrm{J}$ 2021;42:3599-726.

5. Djordjevic T, Arena R, Guazzi M, Popovic D. Prognostic value of NTPro Brain natriuretic peptide during exercise recovery in ischemic heart failure of reduced, midrange, and preserved ejection fraction. J Cardiopulm Rehabil Prev 2021;41:282-7.

6. Markus MRP, de Freitas HFG, Chizzola PR, et al. Massa ventricular esquerda em portadores de insuficiência cardíaca. Arq Bras Cardiol 2004;83:227-31.

7. Gardin JM, McClelland R, Kitzman D, et al. M-mode echocardiographic predictors of six- to seven-year incidence of coronary heart disease, stroke, congestive heart failure, and mortality in an elderly cohort (the Cardiovascular Health Study). Am J Cardiol 2001;87:1051-7.

8. Gradman AH, Alfayoumi F. From left ventricular hypertrophy to congestive heart failure: management of hypertensive heart disease. Prog Cardiovasc Dis 2006; 48:326-41.

9. Cebeci E, Samancı NŞ, Uzun S, et al. Inflammation, left ventricular mass Index and chronic renal failure in diabetic patients. Haseki Med Bull 2020;58:129-34.
10. Santosa YP, Tjandrawati A, Noormartany, et al. Comparison of pro B-natriuretic peptide in hypertensive patients with and without diastolic dysfunction. Acta Med Indones 2008;40:19-23.

11. İltümür K, Karabulut A, Toprak N. İzole diyastolik disfonksiyonda NtProbnp. Dicle Med J 2005;32:165-71.

12. Lang RM, Bierig M, Devereux RB, et al. Recommendations for chamber quantification: A report from the American society of echocardiography's guidelines and standards committee and the chamber quantification writing group, developed in conjunction with the European association of echocardiography, a branch of the European society of cardiology. J Am Soc Echocardiogr 2005; 18:1440-63.

13. Devereux RB, Alonso DR, Lutas EM, et al. Echocardiographic assessment of left ventricular hypertrophy: comparison to necropsy findings. Am J Cardiol 1986;57:450-8.

14. Rørth R, Jhund PS, Yilmaz MB, et al. Comparison of BNP and NT-proBNP in Patients With Heart Failure and Reduced Ejection Fraction. Circ Heart Fail. 2020;13:e006541.

15. Lubien E, DeMaria A, Krisnaswamy P. Utility of B-natriuretic peptide in detecting diastolic dysfunction: comparison with Doppler velocity recordings. Circulation 2002;105:595-601.

16. Uraizee I, Cheng S, Hung CL, et al. Relation of N-terminal pro-B-type natriuretic peptide with diastolic function in hypertensive heart disease. Am J Hypertens 2013;26:1234-41.

17. Talwar S, Siebenhofer A, Williams B, Ng L. Influence of hypertension, left ventricular hypertophy, and left ventricular systolic dysfunction on plasma N terminal proBNP. Heart 2000;83:278-82.

18. Huang L, Huang L, Yu J, Wu X, Zhao J. An association between N-terminal pro-brain natriuretic protein level and risk of left ventricular hypertrophy in patients without heart failure. Exp Ther Med 2020;19:3259-66.

19. Rivera Otero JM, Taléns-Visconti R, Salvador A, et al. Ventricular hypertrophy increases NT-proBNP in subjects with and without hypertension. Int J Cardiol 2004;96:265-71.

20. Morillas P, Castillo J, Quiles J, et al. Usefulness of NT-proBNP level for diagnosing left ventricular hypertrophy in hypertensive patients. A cardiac magnetic resonance study. Rev Esp Cardiol 2008;61:972-5.

21. Welsh P, Poulter NR, Chang CL, et al. The value of N-terminal pro-B-type natriuretic peptide in determining antihypertensive benefit: observations from the Anglo-Scandinavian Cardiac Outcomes Trial (ASCOT). Hypertension 2014;63:507-13. 